Article

\title{
Towards Intergenerational Equity: Analysis of Youth Engagement Strategies in Climate Action Planning in Mzuzu, Malawi
}

\author{
Josephine Marion Zimba ${ }^{1, *}$, Brian Simbeye ${ }^{2}$ and Stanley Chilunga Chirwa ${ }^{2}$ \\ ${ }^{1}$ Environmental Science and Management Department, Lilongwe University of Agriculture and Natural Resources, Malawi; \\ E-Mail: jzimba@luanar.ac.mw \\ 2 Independent Researchers, Malawi; E-Mails: briansimbeye9@gmail.com (B.S.), stanleychirwa7@gmail.com (S.C.C.) \\ * Corresponding author
}

Submitted: 19 April 2021 | Accepted: 19 July 2021 | Published: 16 December 2021

\begin{abstract}
Globally, meaningful youth participation in planning processes aimed at dealing with climate change impacts has been advocated for sustainability purposes. Article 6 of the United Nations Framework Convention on Climate Change requires parties to ensure there is public participation in addressing climate change, its effects, and the development of responses. In the city of Mzuzu, Malawi, local community members have been involved in planning processes at different planning levels but more intensively at the community level. Despite this approach receiving much attention, minimal consideration has been put on which societal groups are to be engaged directly, with youths being excluded to a large extent, even though about $49 \%$ of the population in Malawi is aged between 10 and 34 years. This article, therefore, seeks to foreground how current stakeholder engagement strategies in climate change planning marginalise the youth. To do this, this article critically reviews current stakeholder engagement strategies and assesses the extent to which youth are involved in the planning processes in Mzuzu City. It further assesses the factors affecting youth involvement in the planning process and subsequently recommends how stakeholder engagement strategies can be designed and implemented to ensure effective youth engagement in climate change planning processes in the city.
\end{abstract}

\section{Keywords}

climate change; Malawi; planning; stakeholder engagement; youth

\section{Issue}

This article is part of the issue "Planning for the Local Impacts of Climate Change: Nobody Left Behind?" edited by Mark Seasons (University of Waterloo, Canada).

(C) 2021 by the authors; licensee Cogitatio (Lisbon, Portugal). This article is licensed under a Creative Commons Attribution 4.0 International License (CC BY).

\section{Introduction}

Article 6 of the United Nations Framework Convention on Climate Change requires parties to ensure there is public participation in addressing climate change, its effects, and the development of responses (United Nations, 1992). Youths form a basic bedrock of society and that calls for their involvement in all initiatives affecting society, from the planning stage to the implementation stage (Oladeji et al., 2017). The involvement of the youth in the planning process often contributes to the speedy and successful implementation of activities (Udensi et al., 2013).
Studies have revealed that several factors affect youth inclusion in planning processes. For countries that have adopted a decentralised system of government to enhance community participation in governance systems such as Malawi, decentralisation to local governance structures is still contributing to a lower level of participation than expected in terms of changing regulatory, administrative, and financial public decisionmaking (Helmsing, 2002). Further, there is a lack of assistance from the government at the grassroots level and inadequate recognition of youths as a formidable labour force in the community (Akinboye et al., 2007). 
Besides the dynamics in the relationship among youths, adults, and institutions (Camino, 2000; Tarifa et al., 2009), socioeconomic factors, inadequate awareness, nonchalant attitude, and selfishness also affect participation (Kaseya \& Kihonge, 2016; Udensi et al., 2013). Youth participation is viewed as a process of allowing young people to contribute to any developmental activity meaningfully and actively within their community (Checkoway \& Gutiérrez, 2006). Although youth in Malawi-those aged between 10 and $34-$ constitute about $48.7 \%$ of the population (National Statistical Office, 2019), their involvement in planning processes including those related to climate change management is minimal.

The United Nations Joint Framework Initiative on Children, Youth and Climate Change (2013) recognises youths as having an increasingly strong social and environmental awareness, and the energy and knowledge to lead societies towards a low carbon and climate-resilient future. The United Nations World Youth Report (United Nations, 2020) indicates that youths, despite being mere beneficiaries of the 2030 Sustainable Development Agenda, are architects when it comes to its development and implementation. This is empowering youths to take a pivotal role in development. However, not all youths have the capacity to take a leading role in development. Active youth participation remains a key issue and is often side-stepped in research due to logistical and ethical concerns (Schelbe et al., 2015; Wattar et al., 2012). In addition, given that by the year 2030 the proportion of youth in developing countries will increase by $62 \%$ (Population Division of the United Nations Department of Economic and Social Affairs, 2019), systematic inclusion of this growing population in the planning process has the potential to lead to the sustainability of the initiatives implemented. Further, the involvement of youth in making decisions regarding climate action is a step towards addressing intergenerational justice by ensuring that people who are most likely going to feel the effects of the current decisions being made are actively involved in the decision-making process. Despite this significant potential, youth inclusion in climate action planning processes is limited. This article, therefore, foregrounds the current gaps in stakeholder engagement strategies and barriers to youth participation in such processes. It recognises how most studies in Malawi target community members as a homogenous entity with minimal consideration on individual societal groups. Furthermore, studies on youth participation in Malawi mostly concern health policy, party politics, economics, and agriculture (Chinsinga \& Chasukwa, 2012; Gondwe et al., 2020; Wigle et al., 2020). Except for the involvement of youth in climate change learning to enhance climate literacy in Malawi (Ministry of Forestry and Natural Resources, Environmental Affairs Department, 2021), little is known about how young people are involved in climate change planning processes. This study, thus, reviews current stakeholder engagement strategies and assess the extent to which youth are involved in the planning processes in
Mzuzu City. It further assesses the factors affecting youth involvement in the planning process and proposes how stakeholder engagement strategies can be designed and implemented to ensure effective youth engagement in climate change planning processes in the city. To achieve a youth-inclusive climate action planning process, this article provides a framework as a step-by-step guide. This framework can potentially be used in countries with similar engagement strategies and decentralised systems of governance.

This study is guided by various theoretical understandings of participation in planning processes. Participatory theory is a broad and complex concept. There has been improvement and adjustment in participatory methodologies, with the 1980s seeing the advancement of bottom-up approaches in contrast to top-down approaches with emphasis on the inclusion of local indigenous knowledge in planning processes (Claridge, 2004). Several theories in participation have informed this study. Firstly, the civic voluntarism model (CVM) views resources, engagement, psychological engagement, issues engagement, and recruitment through networks as prerequisites for effective participation (Barkan, 2004; Burns et al., 2001). Although developed in relation to political participation, this model is relevant in other planning processes. Using this model, people participate if they have access to resources such as time, money, and civic skills. This understanding of participation is arguably linked to studies that associate socio-economic status and educational background with levels of meaningful participation in planning processes (Angba et al., 2009; Corner et al., 2015; Mohamud et al., 2018). Even though others might possess these resources, the level of participation might be not as expected (Rubenson, 2000). Resources alone might not be enough to guarantee participation.

Psychological engagement means people should be self-interested and motivated to take part in the processes (Barkan, 2004). In this case, for youth to participate in local planning processes, they need to have the attitude and "inner drive" to participate. This is closely associated with issues engagement, another component of the CVM that concerns the relevance or significance of the processes to the participants (Barkan, 2004). For youth to participate in local climate action planning, they need to be convinced of how such processes will benefit them. Yet, psychological and issues engagement would only be possible if the individuals are well-informed of climate change impacts and the existence and relevance for local planning processes. Finally, recruitment through personal networks plays a role in participation. Youths with connections to various relevant institutions are more likely to participate in planning processes. We, therefore, argue that the way current stakeholder engagement strategies are employed in Mzuzu City restricts the recruitment of youth in local climate action planning processes. Further, other factors such as culture, attitudes, and awareness, which border 
on psychological and issues engagement lead to minimal participation of the youth.

Being included in planning processes alone does not entail meaningful participation. As Arnstein (1969) noted, the extent of participation varies from the minimal levels of non-participation (manipulation and therapy) through tokenism (information, consultation, and placation) to citizen control (partnership, delegation, and citizen control). This model is akin to Pretty's model of 1995 (Pretty, 1995; Tosun, 2004). Each level in the participation ladder corresponds to the decision-making power present at that level, with increased decisionmaking power at higher levels of participation. Based on Arnstein's work, several authors have developed further models to better theorise citizen participation. These models include a new ladder to citizen participation (Connor, 1988), the split ladder of participation (Hurlbert \& Gupta, 2015) and an "extended" Arnstein's ladder (Kotus \& Sowada, 2017), among others. Despite sharing a common critique on Arnstein's ladder as being too simplistic to explain the participation process, this article draws from the consensus among this scholarship to argue that meaningful participation is congruent to the extent of participation, with lower levels proving insignificant for local climate action planning processes.

Considering the foregoing, this article draws from the general incentives model of participation (Adhikari et al.,
2014) to develop a framework for designing and implementing a youth-inclusive stakeholder engagement process. Different studies have looked at various incentives as a factor affecting a community's participation in activities (Hobbs \& White, 2012; Wehn \& Almomani, 2019). It proposes how to design and implement stakeholder engagement processes that disinhibit and encourage youth participation in local climate action planning processes. For this study, stakeholder engagement processes are all activities/approaches used to involve different stakeholders in the planning of local climate action.

\section{Methodology}

\subsection{Description of the Study Area}

Mzuzu City (Figure 1), located in Mzimba District, is the third-largest urban centre in Malawi, after Lilongwe and Blantyre, respectively. The city has a fast-growing population with an intercensal annual growth rate of $5.4 \%$, the highest among cities in Malawi (National Statistical Office, 2019).

Mzuzu City has been experiencing an increase in disasters such as floods, landslides, and strong winds since the early 2000s (Kita, 2017). The city recorded the worst flood disaster in its history in 2016, whereby more than 1,900 people were displaced. Out of the 15

MAP OF MALAWI SHOWING MZUZU CITY

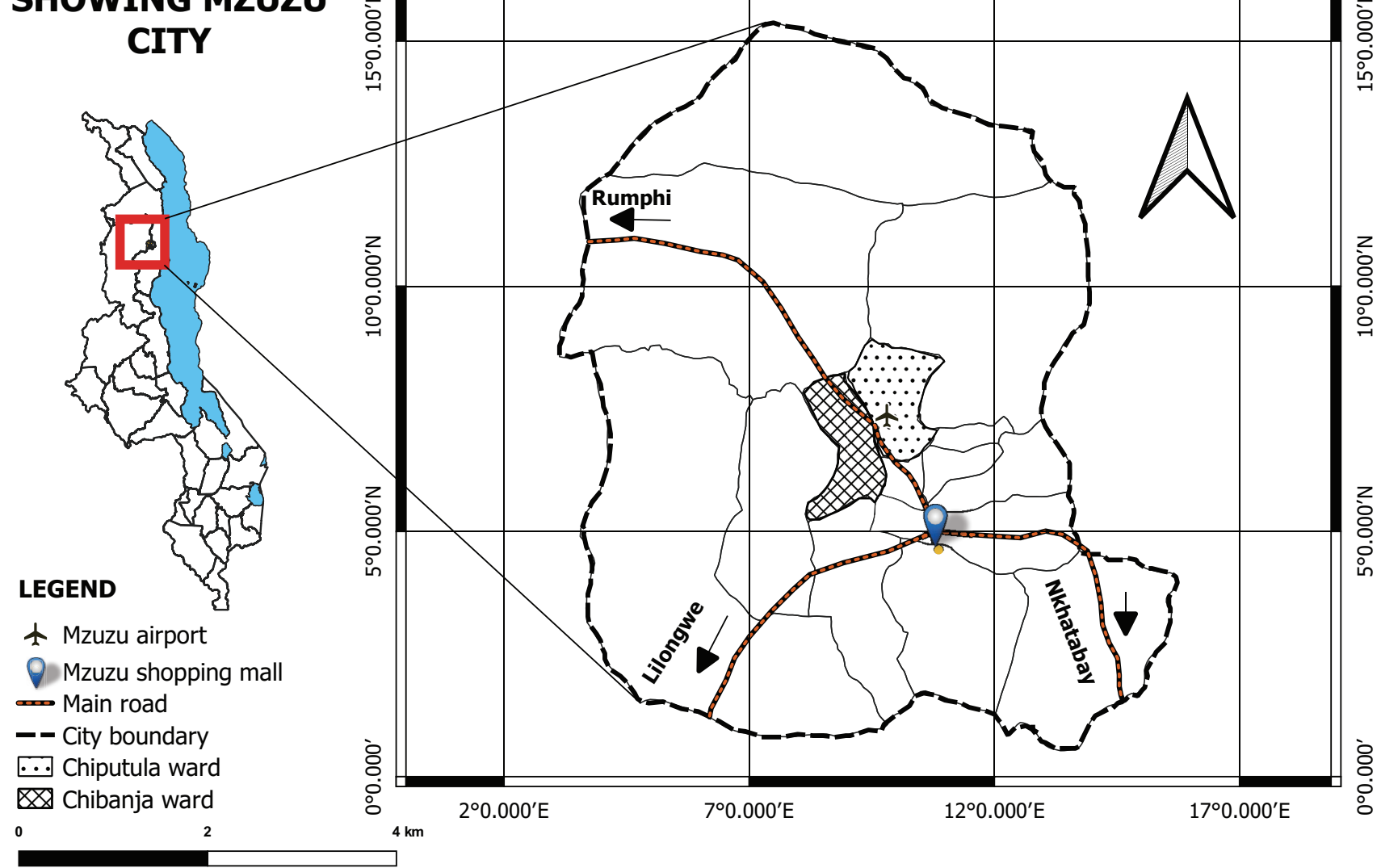

Figure 1. Map of the study area. 
wards in Mzuzu City, five wards are highly vulnerable to climate-related disasters (Malawi Red Cross Society, 2019). The empirics of this study, however, are from two of the five wards, Chibanja and Chiputula, chosen because of the high frequency of floods and their associated severe impacts.

\subsection{Data Collection and Analysis}

To achieve the research aims, the study employed qualitative data approaches as they are ideal to answer why and how a social phenomenon occurs and the underlying causes of the phenomenon (Kaae \& Traulsen, 2015). This was done through focus group discussions and in-depth key informant interviews conducted between August 2020 and January 2021. All participants in the focus group discussions gave verbal consent to participate in the research. Except for two key informants, four participants provided verbal consent to the interview. Focus group discussions were used because of their robustness in the in-depth exploration into the shared and unshared opinions, knowledge, perceptions, and concerns of individuals regarding a particular topic (Seal et al., 1998; Waste Programs Sub-Workgroup for Community Engagement, 2017). In each ward, two focus group discussions were conducted, one with youths and the other with Ward Civil Protection Committee (WCPC) members. Each group was comprised of 12 members. For the youth group, the study targeted those aged between 18 and 35 who had been residents in the study area for at least five years. Such participants were perceived to be knowledgeable of the area and climate governance practices therein. Snowballing sampling technique was used to identify youth participants whereby community leaders, as well as the youths, were asked to identify those youths who are active in community projects. As for the WCPC, the only requirement was being a member.

Further, in-depth key informant interviews with four key NGO officials and two government officials undertaking climate change interventions in Mzuzu City were also conducted. Informed by the aims of the study, a checklist was designed and used to guide all interviews. The interview guide for the youth and WCPC focus group discussion aimed at capturing community participation and youth engagement. Questions that sought to understand how and when the community is involved were used for the former theme, and questions that sought to source information on how the youth are engaged and how they participate in climate action planning and implementation activities were used for the latter theme. The interview guide for the key informant interview aimed at capturing current stakeholder engagement strategies, community participation, and youth engagement in climate action planning processes, with questions that targeted the approaches used by the respective organisation in engaging communities and further questions that sought to capture the level of dedication to climate action by the communities.
All interviews were recorded using a voice recorder. The recordings were translated from Chitumbuka and Chichewa languages and transcribed verbatim into English. Following Taylor-Powell and Renner (2003), the data was coded/categorised and coherent themes were identified which revealed patterns and connections within and between categories. It was based on these themes that interpretation of the data was made.

\section{Results and Discussion}

\subsection{Current Stakeholder Engagement Strategies}

The principal resource for responding to climate change impacts is public support, the people's knowledge, and expertise (Conde et al., 2004; Moser \& Pike, 2015). Different institutions take slightly different approaches when engaging stakeholders. All participants reported consultations as the major form of engagement whereby the stakeholders were mostly just given information about the intended interventions for them to relay to their respective community members. Based on Arnstein (1969), this is still at the tokenistic level, which is insignificant for meaningful participation. However, further analysis of the data revealed the following three engagement strategies employed in Mzuzu City.

\subsubsection{The Use of Established Local Government Structures}

Most stakeholder engagement strategies target local governance structures at the sub-city level (Figure 2). In the decentralised governance structure, the Ward Development Committee is the key committee at the community level which leads the identification and implementation of development activities in the ward. Since the most common climate change-related impacts experienced in Mzuzu are floods, the local disaster risk management structure, i.e., civil protection committees, are often engaged. These committees are aligned with development structures at the neighbourhood, ward, and city level. The WCPC is a vital structure actively and widely engaged by institutions implementing climate change interventions. Stakeholders prefer the use of preexisting community structures for engagement purposes since the use of local resources ensures that communication and activities are well-targeted and reflect community interests and capacity (Wiseman et al., 2010), which are important prerequisites for implementation success.

Noting the impracticality of always engaging all community members, the WCPC is mainly engaged as a representative of the community, a role that also involves making decisions on behalf of the communities. In this regard, some institutions only engage WCPC members in their planning processes and take their views as those of the community. In other cases, the decision-making role extends to the identification of participants for engagement activities. As one NGO official put it: "For the times 


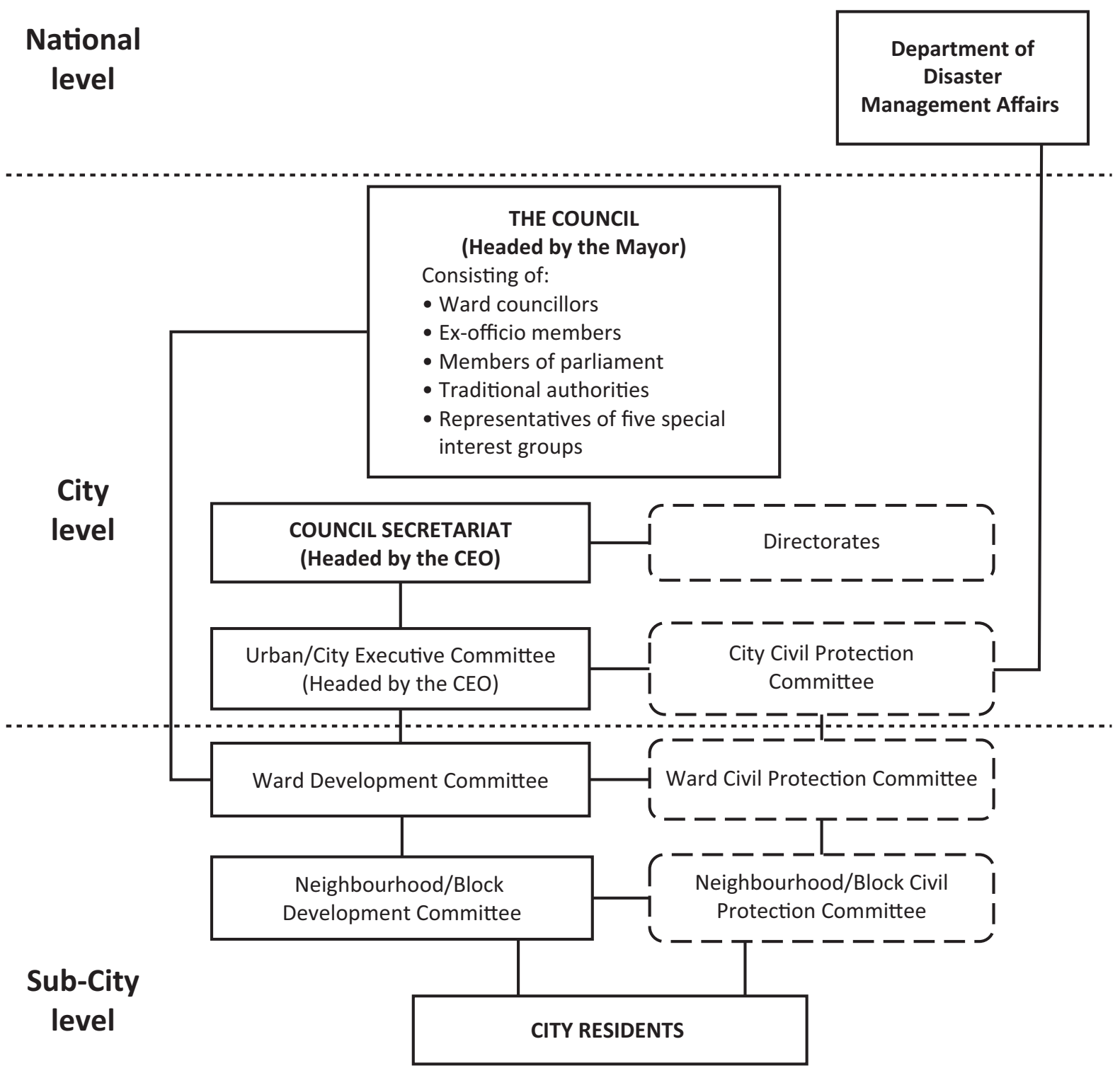

Figure 2. Local government structure. Source: Author's work, adapted from Ministry of Local Government and Rural Development (2013).

that we use the local structure, we often go through the WCPC. They are the ones who identify the participants as per the groups we need whether youths or women, or anyone."

This use of the community structures as representatives of the people, along with the assumed power they have, leaves the engagement strategy prone to elite capture. This is problematic, as elite capture inhibits citizen engagement in local governance processes (Waheduzzaman et al., 2018). During the study, most youths reported issues of favouritism where only those known to the WCPC members and community leaders are involved in engagement processes.

\subsubsection{Direct Engagement With Youth Groups/Clubs}

Approaches to stakeholder engagement vary and are heavily dependent on the issue being tackled. For inter- ventions that specifically target youths, some implementing organisations approach the youths directly through youth clubs. Responses from youth and NGO officials alike revealed that when there is direct engagement, the youths are motivated and they dedicate themselves fully to the process, which ensures project success and sustainability. However, this approach benefits only those who are in clubs or have formulated youth groups. As one NGO official elaborated:

We target youths where they meet simply because when you target them individually it will be difficult to say we are working with these youths. Working with youth who are already organised in structures makes it easier to plan, implement, and monitor the impact of initiatives than with separate individuals from their homes. 
As most of the climate action-planning processes are undertaken under existing projects, the findings show that the implementers are focused on the success of the project within the project implementation period, which makes it difficult for them to mobilise the youths in the communities. The youth groups, therefore, simplify the task of implementation and monitoring of planning processes. One major flaw with this arrangement is that only the very same youths are engaged over time. Those that are not in youth clubs, for various reasons, are kept out of the planning and implementation processes.

\subsubsection{Use of Individual Community Leaders}

Community leaders such as chiefs, block leaders, and ward councillors, are often engaged as key stakeholders in the community. Participants reported that these community leaders are usually involved as key informants during consultations and serve as information channels to the community members on planning and implementation processes. This strategy has proven to work to some extent as partnerships with local and well-respected people can usefully strengthen community engagement activities and outcomes (Wiseman et al., 2010). Most respondents observed that the inclusion of community leaders, as information channels, encourages local ownership and support because the leader's words or views are widely accepted and respected by the community.

With the perception that community leaders have vast knowledge of their community, sometimes they are tasked with stakeholder identification for the planning process. This strategy is problematic. Most youth participants reported that this approach enables leaders to prioritise their close friends, party supporters, and relations in the selection of participants regardless of their abilities to contribute effectively to the discussions. This, therefore, leads to the exclusion of people who would effectively contribute to the initiative's success. Projects that followed this procedure mostly got negative feedback during evaluation. One participant reported a project that was given negative appraisal from community members which affected its further implementation. This practice defeats the purpose of meaningful stakeholder participation which aims to allow stakeholders to plan and influence programs in the planning process.

\subsection{Factors Affecting Youth Engagement in Local Climate Action Planning Processes}

\subsubsection{Inadequate Awareness of Climate Action Planning Processes}

Most of the youths within the study areas have limited information regarding the existing planning processes for climate action. During the youth focus group discussions in both wards, the youth reported that they are aware that climate action planning activities happen in their communities. However, they do not know when they are scheduled to take place and how they could get involved. An NGO official concurred:

The problem we have about youths is that our youth lack exposure and information which affects productivity to participate in developmental activities.... I will give you an example of social incubators where we have few youths attending because they don't know that they can join social incubators. That's the problem.

This problem is not only exacerbated by the lack of coordination between local governance structures and youth clubs, but also the lack of formalisation of the youth clubs as part of the existing local governance structures. According to Fedessa et al. (2018), a lack of information results in a low level of awareness when it comes to developmental activities in the community. Youth are eager to participate in planning processes if there is proper sensitisation in the communities on what is happening, what role they will take, and how it will benefit them.

\subsubsection{Cultural Aspects}

Adults in Mzuzu City often take the leading role in planning processes and constitute the majority of participants in the community. Akin to most African societies, youths, when invited to a village meeting or any planning process, find it hard to express themselves and debate on important issues with elders within the group, as one youth participant explained:

Culturally, it is impossible to have an exchange of words or debate with elders... this is seen as a lack of respect....When the youth express themselves, their views are often not taken on board. As such, they fail to make significant contributions even though they are insightful.

Youth occasionally interact with adults and when involved with adults, it is within a prescribed limit because they are bound by culture (Mohamud et al., 2018). Such intergenerational factors limiting youth participation in Malawi have also been observed in other sectors (Mchakulu, 2007). In Mchakulu's study, the youth would either moderate their responses to stay within the expected cultural norms or completely avoid differing from the elder's opinion altogether. Such sociocultural contexts ought to be understood when designing planning processes in the community (Camino, 2005; Ungar, 2013).

\subsubsection{Scheduling of Engagement Activities}

The day of the week or the time at which climate action planning processes occur affect youth participation. Planning processes targeting weekdays are a challenge to most youths. This is the time most of the youth are in schools or at work. Youths from this study 
expressed how time affects their participation:

People from the city council and other organisations used to just come during the week, so we told them that when putting your own programs, you have to consider the people you are meeting. The fact that this is a community does not mean we have nothing to do. There are people, especially the youths, who go to school, some run small scale businesses, and others go for piece work to earn a living.

Most youths easily participate meaningfully and actively when the planned time is in line with their availability in general. The preferred day for the youth which increases the chances of participation is Saturday. As one of the participants of the youth focus group discussion put it:

We have had some activities conducted on Saturdays, early in the morning, before anyone goes to church or other activities. They announce a day or more before the day of the activity. So, it's a matter of waking up early and doing your part (participate in the activity/deliberations) then proceed to your personal activities.

These findings are consistent with those of a study by Kaseya and Kihonge (2016) in Kenya, in which they found that the day of the week the forum is scheduled affected people's participation in development activities. In their study, over $80 \%$ of participants preferred participation activities to be conducted during weekends rather than weekdays. Therefore, the scheduling of stakeholder engagement events on weekdays is a significant factor affecting youth participation.

\subsubsection{Youth's Attitudes and Characters}

The study found that incentives "obsession" and lack of unity among youths are some of the factors affecting youth participation. Most youths opt to participate only in activities that bring money. Although a study by Collins et al. (2008) found that incentives can motivate teens to be interested in out-of-school activities, incentives have shown to be Janus-faced. A key informant in this study narrated how incentives have negatively affected youth participation:

Youths got used to receiving money, so when no money is attached to a project, they don't show up....They say when good things come, we don't involve them but we invite them when there are voluntary activities....That thinking is what causes more youth not to show up during climate action planning processes.

Furthermore, lack of commitment by most of the youth has resulted in them being side-lined during planning processes. Most officials from NGOs mentioned the lack of commitment from youth as one big challenge. They indicated that when involved, most youths do not even contribute as much as expected, with one official reporting a young person responding to an invitation to participate as "something for the elderly, not youth." This attitude, however, is evidence of subject political culture prevalent in Malawi, which is "characterised by elements of indifference and/or passivity among citizens inspired by the recognition that they have a very limited capacity to influence the content and strategic aspects of public policy" (Chingaipe \& Msukwa, 2012, p. 30). This culture is often linked to politics of paternalism from the one-party system and the top-down approaches that continue to be used in the multiparty dispensation.

\subsection{Towards a Youth-Inclusive Stakeholder Engagement Strategy in Local Climate Action Planning Process}

Stakeholder theory requires that leaders understand and incorporate the interests of stakeholders in their operations. In this study and the framework presented in this section, stakeholder engagement is understood as "any process that involves stakeholders in some form of collaborative effort directed towards a decision, which might involve future planning and/or behaviour change" (Gardner et al., 2009, p. 11). Often, inclusive governance practices involve "information-seeking practices" (Brown, 2002, p. 373). Drawing from the experiences and findings of this study, however, this article strongly opines that effective youth engagement requires purposive and deliberate strategies in the design and implementation of stakeholder engagement strategies. This section outlines a framework to guide the organisation and implementation of climate action planning processes to ensure that they are youth inclusive. Figure 3 presents the process of a youth-inclusive local climate action planning process. The framework is presented to correspond to the climate action planning processes implemented in the area. It is envisaged that if the youth inclusion practices are integrated in the action planning process, implementation will not only be less cumbersome but also cost-effective.

For stakeholder-engagement strategies to be youth-inclusive and enhance effective youth participation, serious attention should be given to both the design/organisation and implementation of the strategies. The processes in the organisation/design stage should be successfully done before the implementation of the engagement activities. The first step is the organisation or designing stage. This step focuses on the preparation or groundwork that should be done before undertaking the particular stakeholder engagement activities. A youth-inclusive process ought to firstly strengthen the engagement capacities of the youth, by training them in not only the subject matter but also active citizenship. On the one hand, training or increased awareness on the subject matter is fundamental as it is only when participants as individuals and collectives are equipped with 


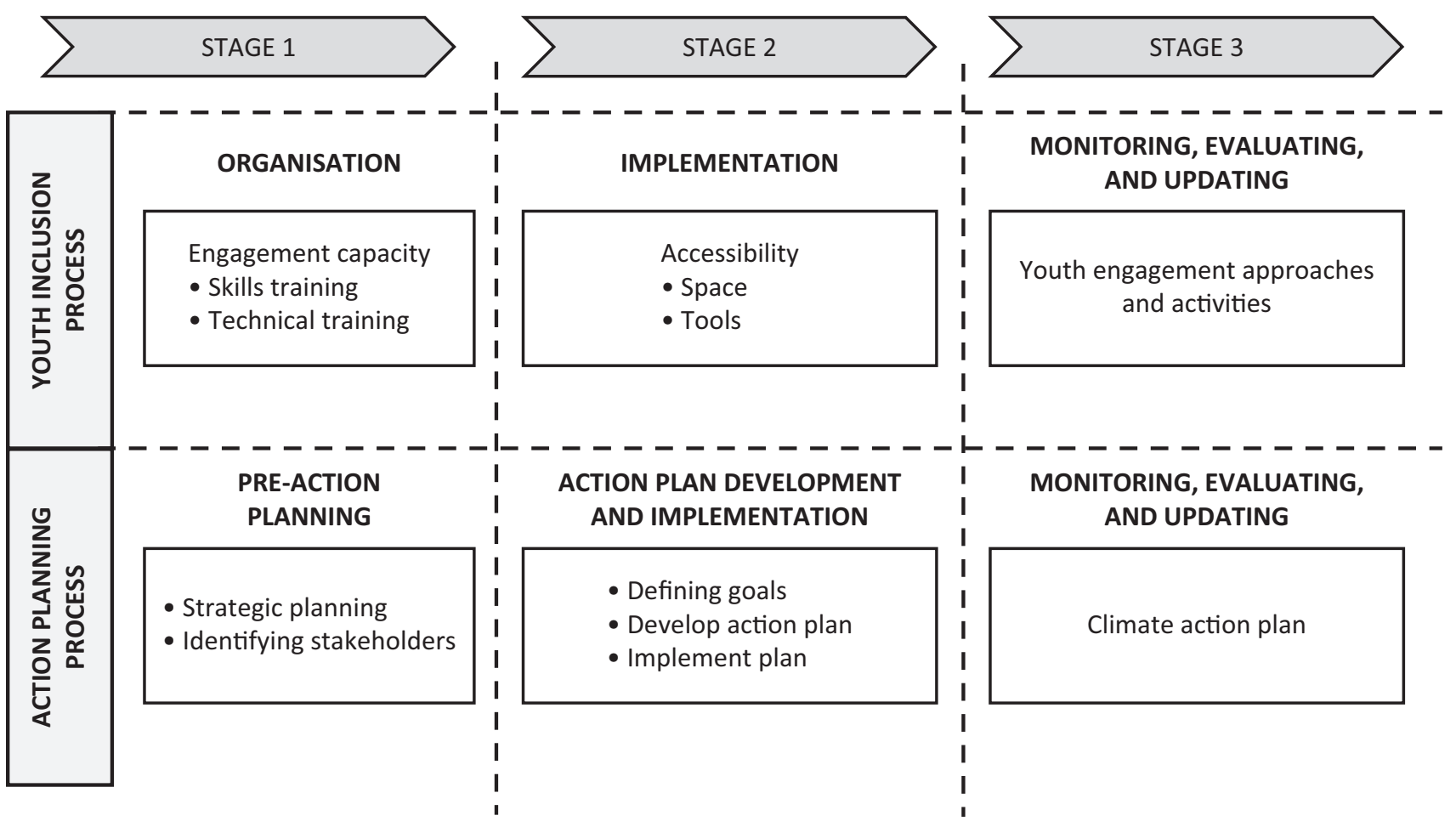

Figure 3. Framework for designing and implementing youth-inclusive stakeholder engagement strategies.

skills and knowledge that they can actively participate in planning processes (Cuthill \& Fien, 2005). Technical training should not only focus on equipping youth with basic concepts used in the climate change discipline but it should also address the current relevant debates in the governance of climate change at the global and local level. On the other hand, strengthening engagement capacity also involves skills training. This may include training in active citizenship as it is critical to equip the youth with relevant negotiation skills to successfully engage in deliberative processes. Besides active citizenship, youths, through the re-energised youth clubs, can be given training in technical and entrepreneurial skills and capital to help them be economically independent. Rather than nurturing the attitude of providing financial incentives to "boost the morale of the respondents and also encourage attendance" (Kaseya \& Kihonge, 2016, p. 486), economically and psychologically empowered youths, arguably, will readily engage in local climate action planning processes.

In line with the CVM and the general incentives model of participation, it is only upon the enhancement of youth engagement capacities that the implementation of engagement activities can be done. Such a comprehensive approach to training will go beyond knowledge exchange and lead to changes in attitudes and behaviour. In the case of Mzuzu City, this can easily be done through reinvigorating youth clubs which are now almost inactive. A vibrant network of youth clubs across the city will ensure that they are represented at all levels in the local planning processes, including at the city council level. Ultimately, increasing engagement capac- ities should increase the levels of engagement and the quality of participation beyond tokenistic levels, which are themselves not beneficial to the process or the participants (Kirby \& Bryson, 2002).

The second stage is the implementation stage. As with engagement activities in other settings, climate action planning processes can take various forms. These range from information-seeking activities such as surveys, to more deliberative activities, such as policydrafting sessions. For an engagement activity to be youth-inclusive, accessibility should be prioritised. Firstly, this can be achieved through the provision of dedicated engagement spaces for the youth. Practically, and considering the cultural barriers mentioned earlier, this entails leading agencies in the local planning processes creating spaces for youth to participate in climate action planning rather than having the youth as part of a bigger group representing the communities. These could be youth-only focus group discussions and planning workshops with participants identified in or through the existing youth clubs. Besides creating youth-targeted spaces, accessibility also focuses on the tools and formats of the engagement activities being implemented. This could include the use of language youth can easily understand and relate to and other creative approaches such as music, drama, and sporting activities. Studies in other sectors such as health have shown that the use of sporting events increases the chances of effective engagement with the youth in Malawi (Michaels-lgbokwe et al., 2015). Hence, extending such an approach to climate action planning processes would make stakeholder engagement strategies 
and climate action planning processes appealing and accessible to the youth.

The final stage involves monitoring, evaluating, and updating the approaches. Akin to various complex processes, youth-inclusion approaches and activities need to be monitored and evaluated to assess the levels of achievement of the set goals. During the implementation processes, lessons must be learnt. It is based on the experiences and lessons learnt that the approaches and activities should be updated to make them more effective in ensuring youth inclusion in climate action planning. This stage should be synchronised with the monitoring and evaluation of the climate action plan developed and implemented for more comprehensive and cost-effective results.

In light of the evidence, therefore, a youth-inclusive process in local climate action planning ought to address the design and implementation of the engagement activities, including underlying constraints. As such, the engagement capacities of the youth should be strengthened, including through technical and skills training. Further, following co-designing of youth-targeted engagement activities, youth-friendly spaces and tools should be used during the implementation of the engagement activities. This should be accompanied by monitoring, evaluation, and constant updating of the approaches and activities based on the lessons learnt.

\section{Conclusions}

The study sought to foreground how current stakeholder engagement strategies in climate action planning marginalise the youth. The findings have revealed significant gaps and barriers in the current stakeholder engagement activities which contribute to the marginalisation of the youth in local climate action planning processes. The use of established local governance structures which are often captured by politicians has meant only youths who are politically connected are involved in planning activities. Additionally, the hunt for monetary incentives, at times, prompts those in authority in the communities not to involve many people, including the youth, even if their participation is required. The article further assessed the factors affecting youth involvement in the planning process which include lack of awareness, cultural aspects, scheduling limitations and youth's attitudes. Considering the foregoing, a framework is, hereby, proposed for designing and implementing stakeholder engagement strategies to ensure effective youth engagement in climate action-planning processes in the city. Such a framework, though developed based on experiences from Mzuzu City, may be applicable in cities sharing similar contextual situations. These include cities in developing countries with similar cultural challenges to youth participation and following decentralised systems of governance. The application of the framework in such areas will require minimal adjustments. For cities with different contexts, practitioners should consider socio- cultural factors such as youth-adult relationships and how the society perceives the youth in action planning processes. Further, the governance context should also be considered. This is particularly important because significant adjustments may need to be made when applying the framework in a study area that follows a centralised system of governance as the current framework was designed based on lessons from a decentralised system of governance.

The empirics in this study are limited to two wards in Mzuzu City and the local disaster risk management structures. Cognisant of the fact that climate change is a cross-cutting issue, it would be helpful to understand how other structures responsible for critical sectors such as urban planning, health, water, and sanitation engage youth in their planning processes. Further research employing an intersectionality approach would also help to understand how multiple factors in youth's lives, such as class, gender, education, religion, or tribe, concurrently affect their ability to participate in local planning processes. Moreover, and for Malawi's case in particular, there is a need to formalise the youth clubs and their links to local structures such as the WCPCs so that youths are kept informed and participate in all planning processes. These youth clubs should further have a network that could represent the youth at the city council level. Such deliberate and strategic arrangements will give the youth more avenues to participate and influence climate action planning processes.

\section{Acknowledgments}

We thank the officials from the Mzuzu City Council for all the administrative support during data collection. We further thank all research participants including organisations and members of the community in the study areas for participating in the study. Last but not least, we are deeply thankful to the anonymous reviewers whose insightful feedback greatly improved this article.

\section{Conflict of Interests}

The authors declare no conflict of interests.

\section{References}

Adhikari, S., Kingi, T., \& Ganesh, S. (2014). Incentives for community participation in the governance and management of common property resources: The case of community forest management in Nepal. Forest Policy and Economics, 44, 1-9. https://doi.org/10.1016/ j.forpol.2014.04.003

Akinboye, O., Ayanwuyi, F., Kuponniyi, F., \& Oyetoro, J. (2007). Factors affecting youth participation in community development in Remo North Government Area of Ogun State. The Social Sciences, 2(3), 307-311. 
Angba, A. O., Adesope, O. M., \& Aboh, C. L. (2009). Effect of socioeconomic characteristics of rural youths on their attitude towards participation in community development projects. International NGO Journal, 4(8), 348-351.

Arnstein, S. R. (1969). A ladder of citizen participation. Journal of the American Planning Association, 35(4), 216-224. https://doi.org/10.1080/ 01944366908977225

Barkan, S. E. (2004). Explaining public support for the environmental movement: A civic voluntarism model. Social Science Quarterly, 85(4), 913-937. https://doi. org/10.1111/j.0038-4941.2004.00251.x

Brown, W. A. (2002). Inclusive governance practices in non-profit organizations and implications for practice. Non-Profit Management and Leadership, 12(4), 369-385.

Burns, N., Schlozman, K. L., \& Verba, S. (2001). The private roots of public action: Gender, equality, and political participation. Harvard University Press.

Camino, L. (2000). Youth-adult partnerships: Entering new territory in community work and research. Applied Developmental Science, 4, 11-20. https://doi. org/10.1207/S1532480XADS04Suppl_2

Camino, L. (2005). Pitfalls and promising practices of youth-adult partnerships: An evaluator's reflections. Journal of Community Psychology, 33(1), 75-85. https://doi.org/10.1002/jcop.20043

Checkoway, B. N., \& Gutiérrez, L. M. (2006). Youth participation and community change. Journal of Community Practice, 14(1/2), 1-9. https://doi.org/10.1300/ J125v14n01_01

Chingaipe, H., \& Msukwa, C. (2012). Whose voice? Citizen participation and influence in public policy processes in Malawi. Malawi Economic Justice Network.

Chinsinga, B., \& Chasukwa, M. (2012). Youth, agriculture and land grabs in Malawi. IDS Bulletin, 43(6), 67-77. https://doi.org/10.1111/j.1759-5436.2012.00380.x

Claridge, T. (2004). Designing social capital sensitive participation methodologies. Social Capital Research. https://www.socialcapitalresearch.com/ wp-content/uploads/2013/01/Social-Capital-andParticipation-Theories.pdf

Collins, A., Bronte-Tinkew, J., \& Burkhauser, M. (2008). Using incentives to increase participation in outof-school time programs. Child Trends. https:// www.childtrends.org/wp-content/uploads/2013/ 05/child_trends-2008_06_18_pi_ostincentives.pdf

Conde, C., Lonsdale, K., Nyong, A., \& Aguilar, Y. (2004). Engaging stakeholders in the adaptation process. In B. Lim \& E. Spanger-Siegfried (Eds.), Adaptation policy frameworks for climate change: Developing strategies, policies and measures (pp. 47-66). Cambridge University Press.

Connor, D. M. (1988). A new ladder of citizen participation. National Civic Review, 77(3), 249-257. https:// doi.org/10.1002/ncr.4100770309

Corner, A., Roberts, O., Chiari, S., Völler, S., Mayrhuber,
E. S., Mandl, S., \& Monson, K. (2015). How do young people engage with climate change? The role of knowledge, values, message framing, and trusted communicators. Wiley Interdisciplinary Reviews: Climate Change, 6(5), 523-534. https://doi.org/ 10.1002/wcc.353

Cuthill, M., \& Fien, J. (2005). Capacity building: Facilitating citizen participation in local governance. Australian Journal of Public Administration, 64(4), 63-80. https://doi.org/10.1111/j.1467-8500.2005.00465a.x

Fedessa, B., Haile, F., \& Mansingh, P. J. (2018). Determinants of youth participation in the community development process in Ambo District, Oromia Region, Ethiopia. IMPACT: International Journal of Research in Applied, Natural and Social Sciences, 6(7), 1-12. http://oaji.net/pdf.html?n=2017/ 491-1533806775.pdf

Gardner, J., Dowd, A.-M., Mason, C., \& Ashworth, P. (2009). A framework for stakeholder engagement on climate adaptation (CSIRO Climate Adaptation Flagship Working Paper No. 3). CSIRO. https://research. csiro.au/climate/wp-content/uploads/sites/54/ 2016/03/3_CAF_WorkingPaper03_pdf-Standard.pdf

Gondwe, S., Kasiya, S., Maulidi, F., \& Munthali, G. T. (2020). Assessment of youth employment initiatives in Malawi: Implementation realities and policy perspective (FARA Research Report Volume 5 No. 6). Forum for Agricultural Research in Africa. https:// research4agrinnovation.org/wp-content/uploads/ 2021/03/assessment-of-youth-employmentinitiatives-in-malawi-implementation-realitiesand-policy-download.pdf

Helmsing, A. H. J. (2002). Decentralisation, enablement, and local governance in low-income countries. Environment and Planning C: Government and Policy, 20(3), 317-340. https://doi.org/10.1068/c0040

Hobbs, S. J., \& White, P. C. L. (2012). Motivations and barriers in relation to community participation in biodiversity recording. Journal for Nature Conservation, 20, 364-373. https://doi.org/10.1016/j.jnc.2012.08. 002

Hurlbert, M., \& Gupta, J. (2015). The split ladder of participation: A diagnostic, strategic, and evaluation tool to assess when participation is necessary. Environmental Science and Policy, 50, 100-113. https://doi.org/ 10.1016/j.envsci.2015.01.011

Kaae, S., \& Traulsen, J. M. (2015). Qualitative methods in pharmacy practice research. In Z.-U.-D. Babar (Ed.), Pharmacy practice research methods (pp. 49-68). Springer. https://doi.org/10.1007/978-3319-14672-0_4

Kaseya, C. N., \& Kihonge, E. (2016). Factors affecting the effectiveness of public participation in county governance in Kenya: A case of Nairobi County. International Journal of Scientific and Research Publications, 6(2), 476-487. http://strategicjournals.com/ index.php/journal/article/viewFile/381/410

Kirby, P., \& Bryson, S. (2002). Measuring the magic? Eval- 
uating and researching young people's participation in public decision making. Carnegie Young People Initiative.

Kita, S. M. (2017). Urban vulnerability, disaster risk reduction and resettlement in Mzuzu City, Malawi. International Journal of Disaster Risk Reduction, 22, 158-166. https://doi.org/10.1016/j.ijdrr.2017.03. 010

Kotus, J., \& Sowada, T. (2017). Behavioural model of collaborative urban management: Extending the concept of Arnstein's ladder. Cities, 65, 78-86. https:// doi.org/10.1016/j.cities.2017.02.009

Malawi Red Cross Society. (2019). Vulnerability and capacity assessment report: Strengthening resilience to disasters in urban and rural Malawi (STRIM) project, Mzuzu City.

Mchakulu, J. E. J. (2007). Youth participation in radio listening clubs in Malawi. Journal of Southern African Studies, 33(2), 251-265. https://doi.org/10.1080/ 03057070701292574

Michaels-Igbokwe, C., Lagarde, M., Cairns, J., \& TerrisPrestholt, F. (2015). Designing a package of sexual and reproductive health and HIV outreach services to meet the heterogeneous preferences of young people in Malawi: Results from a discrete choice experiment. Health Economics Review, 5(1), 15-17. https:// doi.org/10.1186/s13561-015-0046-6

Ministry of Forestry and Natural Resources, Environmental Affairs Department. (2021). Malawi's strategy on climate change learning. Government of Malawi. https://www.uncclearn.org/wp-content/uploads/ 2021/02/Updated-Malawis-Strategy-on-ClimateChange-Learning-2021.pdf

Ministry of Local Government and Rural Development. (2013). Guidebook on the local government system in Malawi. Government of Malawi. https:// www.resakss.org/sites/default/files/Malawi MLGRD 2013 Guidebook on the Local Government System in Malawi.pdf

Mohamud, A. J., Muturi, P. W., \& Samantar, M. S. (2018). Factors influencing youth participation in community development initiatives of Garowe District. International Journal of Social Science and Economic Research, 3(3), 1107-1145.

Moser, S. C., \& Pike, C. (2015). Community engagement on adaptation: Meeting a growing capacity need. Urban Climate, 14, 111-115. https://doi.org/ 10.1016/j.uclim.2015.06.006

National Statistical Office. (2019). Malawi population and housing census report-2018. Government of Malawi. http://www.nsomalawi.mw/images/stories/ data_on_line/demography/census_2018/2018 Malawi Population and Housing Census Main Report.pdf

Oladeji, J. O., Olaore, O. M., \& Fapojuwo, O. E. (2017). Participation of rural youths in community development process in Osun State, Nigeria. Nigerian Journal of Rural Sociology, 17(2), 51-57.
Population Division of the United Nations Department of Economic and Social Affairs. (2019). World population prospect 2019: Ten Key findings. United Nations. https://population.un.org/wpp/Publications/Files/ WPP2019_10KeyFindings.pdf

Pretty, J. N. (1995). Participatory learning for sustainable agriculture. World Development, 23(8), 1-7. https:// doi.org/10.1016/0305-750X(95)00046-F

Rubenson, D. (2000, April 14-19). Participation and politics: Social capital, civic voluntarism, and institutional context [Paper presentation]. ECPR Joint Sessions of Workshops, Copenhagen, Denmark.

Schelbe, L., Chanmugam, A., Moses, T., Saltzburg, S., Williams, L. R., \& Letendre, J. (2015). Youth participation in qualitative research: Challenges and possibilities. Qualitative Social Work, 14(4), 504-521. https:// doi.org/10.1177/1473325014556792

Seal, D. W., Bogart, L. M., \& Ehrhardt, A. A. (1998). Small group dynamics: The utility of focus group discussions as a research method. Group Dynamics: Theory, Research, and Practice, 2(4), 253-266. https:// doi.org/10.1037//1089-2699.2.4.253

Tarifa, T., Machtmes, K., Fox, J. E., \& Johnson, E. (2009). Factors affecting youth voice in decision-making processes within youth development programs. Journal of Youth Development, 4(4), 85-99. https://doi.org/ 10.5195/jyd.2009.244

Taylor-Powell, E., \& Renner, M. (2003). Analyzing qualitative data. University of Wisconsin-Extension. https://cdn.shopify.com/s/files/1/0145/8808/4272/ files/G3658-12.pdf

Tosun, C. (2004). Expected nature of community participation in tourism development. Tourism Management, 27, 493-504. https://doi.org/10.1016/ j.tourman.2004.12.004

Udensi, L., Daasi, G. L., Emah, D., \& Zukbee, S. (2013). Youth participation in community development (CD) programmes in Cross River State: Implications for sustainable youth development in Nigeria. IOSR Journal of Humanities and Social Science, 13(5), 61-67. https://doi.org/10.9790/0837-1356167

Ungar, M. (2013). The impact of youth-adult relationships on resilience. International Journal of Child, Youth and Family Studies, 4(3), 328-336. https://doi. org/10.18357/ijcyfs43201312431

United Nations. (1992). United Nations framework convention on climate change. https://unfccc.int/ resource/docs/convkp/conveng.pdf

United Nations. (2020). World youth report: Youth social entrepreneurship and the 2030 agenda. https:// www.un.org/development/desa/youth/wpcontent/uploads/sites/21/2020/07/2020-WorldYouth-Report-FULL-FINAL.pdf

United Nations Joint Framework Initiative on Children, Youth and Climate Change. (2013). Youth and climate change: A generational challenge. United Nations. https://www.un.org/esa/socdev/documents/youth/ fact-sheets/youth-climatechange.pdf 
Waheduzzaman, W., As-Saber, S., \& Hamid, M. B. (2018). Elite capture of local participatory governance. Policy and Politics, 46(4), 645-662. https://doi.org/ 10.1332/030557318X15296526896531

Waste Programs Sub-Workgroup for Community Engagement. (2017). Community engagement strategy: Issues to consider when planning and designing community engagement approaches for tribal integrated waste management programs. Tribal Infrastructure Task Force. https://www.epa.gov/sites/default/ files/2017-03/documents/tribalswcommunity engagementstrategy508.pdf

Wattar, L., Fanous, S., \& Berliner, P. (2012). Challenges of youth participation in participatory action researchMethodological considerations of the Paamiut Youth Voice research project. International Journal of Action Research, 8(2), 185-212. https://doi.org/ 10.1688/1861-9916_IJAR_2012_02_Wattar
Wehn, U., \& Almomani, A. (2019). Incentives and barriers for participation in community-based environmental monitoring and information systems: A critical analysis and integration of the literature. Environmental Science and Policy, 101, 341-357. https://doi.org/ 10.1016/j.envsci.2019.09.002

Wigle, J., Paul, S., Birn, A. E., Gladstone, B., \& Braitstein, P. (2020). Youth participation in sexual and reproductive health: Policy, practice, and progress in Malawi. International Journal of Public Health, 65(4), 379-389. https://doi.org/10.1007/s00038020-01357-8

Wiseman, J., Williamson, L., \& Fritze, J. (2010). Community engagement and climate change: Learning from recent Australian experience. International Journal of Climate Change Strategies and Management, 2(2), 134-147. https://doi.org/10.1108/ 17568691011040399

\section{About the Authors}
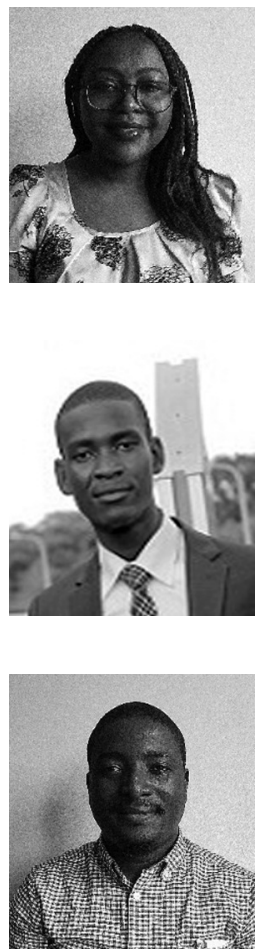

Josephine Marion Zimba is a PhD student whose research borders on the environment and sustainable development nexus. She holds an MSc in Climate Change and Sustainable Development and is a lecturer at the Lilongwe University of Agriculture and Natural Resources. Her current research focuses on urban vulnerability and responses to climate change. Her previous research has been on farmers' adaptation to climate change. Overall, Josephine's research speaks to how communities respond and increase their resilience to environmental changes.

Brian Simbeye is an environmentalist and an independent researcher. His research interests are in climate change and natural resources management with a special focus on how global environmental challenges impact people and the natural environment, and the interplay of policy issues in bringing about informed and sustainable solutions that are people-centred. His current research agenda is to understand the role of inclusive institutions in climate action at the local level.

Stanley Chilunga Chirwa is a climate change science expert and an upcoming researcher in environment-related research. His broader research interests are in assessing climate change impacts on socio-ecological systems and their responses. His previous research is on the assessment of water resource's response to future climate variability. Central to his research agenda is the quest for a deeper understanding of the governance aspect in responding to climate change impacts in the Global South. 